\title{
Relacja między systemem językowym i jego realizacjami w gramatyce konstrukcji
}

Słowa klucze: gramatyka konstrukcji; system oparty na uzusie; konstrukcja; konstrukt

Keyw ords: Construction Grammar; usage-based system; construction; construct

Oczywiste jest, że twórcza inspiracja ideami poprzedników, zarówno przez ich zastosowanie czy modyfikację, jak i przez polemikę z nimi, ma ogromną rolę w rozwoju każdej gałęzi humanistyki. Myśl Ferdinanda de Saussure’a ukształtowała nowoczesne językoznawstwo i dotyczy kwestii tak podstawowych, że jej ślady można odnaleźć w najróżniejszych współczesnych koncepcjach językoznawców, nawet jeśli ich twórcy nie powołują się na de Saussure'a wprost.

Celem niniejszego artykułu jest przedstawienie gramatyki konstrukcji jako przykładu ujęcia relacji między systemem językowym a jego realizacjami we współczesnych modelach języka, które rozwijają i modyfikują rozróżnienie langue i parole de Saussure'a. Gramatyka konstrukcji zaliczana jest do nurtu kognitywnego w językoznawstwie (por. Croft 2007; Geeraerts, Cuyckens 2007), w którym istotny jest konceptualny, funkcjonalny, komunikacyj- 
ny i społeczny wymiar języka (Goldberg 2013: 16), stąd problem relacji systemu do jego realizacji w użyciu rysuje się tu bardzo wyraziście.

Trzeba na wstępie zaznaczyć, że od lat 80. XX w., kiedy to Charles Fillmore i jego współpracownicy (Fillmore 1988; Fillmore, Kay, O’Connor 1988) przedstawili pomysł gramatyki konstrukcji jako wizję opisu języka polemiczną wobec pewnych aspektów gramatyki generatywnej w ujęciu Chomsky’ego, konstrukcyjne myślenie o opisie języka rozwinięto w różnych kierunkach, i obecnie można mówić o całej rodzinie podejść konstrukcyjnych (por. Goldberg 2006: 213-226; Hoffmann, Trousdale 2013: 5-8) ${ }^{1}$. W niniejszym artykule bardzo skrótowo zostaną zarysowane tylko wybrane założenia ogólne wspólne dla różnych konstrukcyjnych opisów języka. Szczególnie interesujące $\mathrm{z}$ punktu widzenia relacji między systemem a jego realizacjami są tzw. kognitywna gramatyka konstrukcji, rozwijana przez A. Goldberg i jej współpracowników (np. Goldberg 1995, 2006; Goldberg, Casenhier, White 2007; Boas 2013), w której szczególnie eksponowane są konstrukcje predykatowo-argumentowe i zagadnienie akwizycji języka w oparciu o jego użycie w kontekście komunikacyjnym, oraz odmiana gramatyki konstrukcji upra-

${ }^{1}$ Choć zagadnienie to wykracza daleko poza temat niniejszego artykułu, warto krótko zasygnalizować, że relacje gramatyki konstrukcji do generatywizmu są złożone i zmieniają się wraz z rozwojem obu nurtów językoznawczych. Z jednej strony gramatyka konstrukcji powstała w opozycji do „głównego nurtu generatywnego” (Goldberg 2006: 4-5) rozumianego jako kolejne wersje teorii transformacyjno-generatywnej Chomsky’ego, prowadzące do współczesnego programu minimalistycznego. Główne różnice podkreślane przez konstrukcjonistów to np. odrzucenie założenia gramatyki uniwersalnej, niederywacyjność opisu konstrukcyjnego, niemodularność systemu, włączenie jako kluczowego elementu opisu języka jego aspektu semantycznego, funkcjonalnego i dyskursowego, dostrzeganie zjawisk ,peryferyjnych” jako wymagających opisu za pomocą tego samego aparatu co zjawiska „bazowe” oraz przypisanie znaczenia strukturom. Z drugiej strony, konstrukcjoniści wpisują w swój program „cel generatywny”, który jest wspólny z gramatyką generatywną, polegający na stworzeniu opisu języka zdającego sprawę ze wszystkich wyrażeń akceptowalnych i możliwości kombinatorycznych języka w sposób w pełni wyartykułowany i ujęty w pewien formalizm (Fried, Östman 2004: 24), a niektóre wersje gramatyk konstrukcyjnych rozwijają ścisły formalizm oparty na założeniu, że konstrukcje to formalizacje zasad łączenia znaków językowych w znaki bardziej złożone (np. Sign-Based Construction Grammar, zainspirowana w pewnych aspektach przez Head-Driven Phrase Structure Grammar, por. Michaelis 2013). Rozumienie relacji konstrukcjonizmu do generatywizmu zależy więc w dużej mierze od interpretacji terminu ,generatywizm” i od wzajemnych wpływów tych podejść w różnych okresach. W ramach nurtu generatywnego pojawił się także tzw. neokonstruktywizm (por. przypis 7 poniżej). 
wiana np. przez M. Fried i J.-O. Östmana, w której akcentuje się kwestie komunikacji, dyskursowej motywacji konstrukcji, rozwoju języka i zjawisk pragmatycznych (np. Fried, Östman 2004, 2005; Fried 2009, por. Hoffmann, Trousdale 2013: 6).

Celem gramatyki konstrukcji jest opis wszystkich konwencji językowych znanych użytkownikom danego języka i używanych w celach komunikacyjnych (Fried, Östman 2004: 15, 23). Kompetencję językową określa się jako znajomość pełnego repertuaru takich konwencji (Fried, Östman 2004: 23). Konwencje zapisywane są jako konstrukcje czyli połączenia formy i znaczenia/funkcji ${ }^{2}$ o różnym poziomie schematyczności, przyswajane w procesie akwizycji języka i przechowywane w pamięci użytkowników (np. Fillmore 1988: 36; Goldberg 2006: 5, 2013: 17)3. W opisie konstrukcji forma może obejmować własności fonetyczne, morfologiczne i/lub składniowe, a znaczenie/funkcja - semantyczne, pragmatyczne i/lub dyskursowe (Croft 2007: 472; Fried, Östman 2005: 1753-1754)4. Konstrukcjami są morfemy, leksemy, idiomy, wzorce frazowe, wzorce zdaniowe, wzorce intonacyjne, wzorce tekstowe (Goldberg, Jackendoff 2004: 532; Fried, Östman 2004: 18; Goldberg 2013: 17). Podejście konstrukcyjne opiera się na założeniu, że konstrukcje tworzą kontinuum elementów o różnym stopniu schematyczności, bez podziału na moduły opisu, w szczególności na leksykon i składnię (Goldberg i Jackendoff 2004: 532; Croft 2007: 468-471). A. Goldberg obrazowo

2 Jedna z pierwszych definicji, sformułowana przez C. Fillmore’a (1988: 36) określa jako konstrukcję każdy wzorzec językowy, z którym związana jest jedna lub kilka skonwencjonalizowanych funkcji; konstrukcja obejmuje też wiedzę o jej językowo skonwencjonalizowanym wpływie na znaczenie lub użycie struktur w których się pojawia.

${ }^{3}$ Dla podjętej tu refleksji nie są istotne kolejne przeformułowania definicji i dyskusje nad precyzyjnym zdefiniowaniem konstrukcji, ani techniczne różnice co do rozumienia tego pojęcia między odmianami gramatyki konstrukcji (por. Hoffmann, Trousdale 2013: 4). Ewolucję definicji konstrukcji opisują np. D. Schönefeld (2006: 17-30) i I. Szymańska (2011: 86-89). Niektóre problemy metodologiczne związane z definiowaniem i wyznaczaniem konstrukcji rozważają I. Szymańska i G. Śpiewak (2006).

${ }^{4}$ Relację takiego ujęcia konstrukcji do znaku (arbitralnego połączenia formy i znaczenia) de Saussure’a i dyskusje na temat rozumienia „formy” w różnych podejściach konstrukcyjnych przedstawia A. Verhagen (2009). T. Hoffmann i G. Trousdale (2013: 1) wskazują, że gramatyka konstrukcji jest próbą rozszerzenia idei znaku de Saussure'a na wszystkie poziomy opisu językoznawczego. 
określa taką koncepcję „constructions all the way down” ('konstrukcje od góry do dołu', Goldberg 2006: 18) ${ }^{5}$.

Konstrukcje są generalizacjami wyłaniającymi się z częstego użycia. Gramatyka konstrukcji określana jest jako system oparty na uzusie ${ }^{6}$ (a usage-based system) (Goldberg 2013: 16; Bybee 2013: 49-51), choć nie we wszystkich jej nurtach ten aspekt jest równie mocno eksponowany (por. Boas 2013: 248-249). Jak podkreślają np. A. Goldberg (2006: 5, 12-14, 63-64), W. Croft (2007: 499-503) czy A. Goldberg i R. Jackendoff (2004: 533), istotną rolę w utrwalaniu wzorców językowych jako konstrukcji w systemie ma częstotliwość ich użycia. Celem opisu jest możliwość wyjaśnienia wszystkich faktów obserwowanych w rzeczywistych danych językowych za pomocą tego samego aparatu teoretycznego (Fried, Östman 2004: 24; Goldberg 2006: 64), bez podziału na zjawiska bazowe i peryferyjne, charakterystycznego dla gramatyki generatywnej. Pojęcie systemu opartego na uzusie odgrywa też kluczową rolę w konstrukcyjnym opisie akwizycji języka, zbieżnym z założeniami kognitywistycznymi. Według konstrukcjonistów w procesie akwizycji system „wyłania” się poprzez kolejne stadia mniejszych i większych generalizacji opartych na danych językowych dostępnych doświadczeniu komunikacyjnemu dziecka. Motywacją tego procesu są znaczenie, funkcjonalność języka oraz potrzeby społeczne i komunikacyjne, stąd wszystkie przyswajane stopniowo konstrukcje, w stadiach pośrednich nie zawsze pokrywające się z konstrukcjami występującymi w kompetencji dorosłych, bardziej czy mniej uogólnione i abstrakcyjne, są znaczące i funkcjonalne (por. np. Tomasello 2003, 2006; Goldberg, Casenhier, White 2007; Diessel 2013).

Przechodząc do bardziej szczegółowego omówienia relacji sytemu do jego realizacji w użyciu, trzeba powiedzieć, że gramatyka konstrukcji precyzyjnie oddziela te kwestie poprzez rozróżnienie między k onstrukcją i konstrukte m. Konstrukcja (construction) to znak symboliczny (połączenie formy i funkcji), abstrakcyjny wzorzec (template/blueprint) przechowywany w reprezentacji mentalnej użytkownika języka. Jest to element systemu licencjonujący użycie wyrażeń stosowanych w komunikacji czyli konstruktów (Fried, Östman 2004: 18). Konstrukt (construct) to rzeczywiste wypowiedze-

5 Jako że niniejszy artykuł poświęcony jest śledzeniu pokrewieństw koncepcji teoretycznych opisu języka, warto wspomnieć, że gramatyka konstrukcji jest w wielu kluczowych aspektach zbieżna z gramatyką operacyjną A. Bogusławskiego (1978).

6 Tłumaczenie terminu angielskiego za M. Tomasello (2003). 
nie (fraza, zdanie, tekst); porozumiewamy się za pomocą konstruktów, które stanowią realizacje konstrukcji. Konstrukt, np. zdanie, jest na ogół realizacją wielu „wpasowanych” w siebie konstrukcji (Goldberg 2006: 10).

Konstrukcje można więc sobie wyobrazić jako wzorce czy schematy $\mathrm{z}$ otwartymi miejscami na wpasowanie innych konstrukcji (Goldberg 2013: 28), czy też obrazowo mówiąc z „haczykami” do „podłączania” innych konstrukcji. Owe miejsca czy „haczyki” określają cechy formalne i funkcjonalne wymagane od ,podłączanych” konstrukcji. Tworzenie nowych, prawidłowych konstruktów opisywane jest jako licencjonowanie (nie jako derywacja), a więc uzgodnienie cech użytego zestawu konstrukcji (Fried, Östman 2004: 25). Interpretacja konstruktu polega na rozpoznaniu użytych w nim konstrukcji - całostek formalno-funkcjonalnych - jako elementów systemu i pogodzeniu niesionych przez nie znaczeń. Istotne jest, że zarówno recepcja, jak i produkcja konstruktów opierają się na rozpoznawaniu całościowych, niosących znaczenie wzorców przechowywanych w pamięci, a nie na składaniu mniejszych elementów w większe według abstrakcyjnych reguł.

Ciekawą cechą gramatyki konstrukcji związaną z wizją relacji systemu do użycia jest możliwość opisania dwóch rodzajów kreatywności w języku. Wizja „wpasowywania” czy nakładania na siebie całych konstrukcji pozwala uchwycić produktywność i kreatywność języka w sensie możliwości tworzenia nieskończonej liczby wypowiedzeń poprawnych, czyli licencjonowanych przez system. Natomiast niektórzy gramatycy konstrukcyjni dostrzegają też drugi rodzaj kreatywności w użyciu języka, który narusza konwencjonalne licencjonowanie, ale który trudno określić jako pomyłkę użytkownika systemu, jest to bowiem na ogół użycie intencjonalne. Chodzi o przypadki niezgodności pomiędzy warunkami określonymi przez konstrukcje i „podłączonymi”" leksemami (Ziegeler 2007: 990). Określa się je czasem jako koercję (coercion "wymuszanie') - obrazowo mówiąc „rozciąganie” (stretching) konstrukcji przez użycie w nich ,nie pasujących” elementów (Fried, Östman 2004: 36-40; Michaelis 2004) w celu tworzenia amalgamatów znaczeniowych (blends) (Dancygier 2011). Ilustracją tego zjawiska w angielszczyźnie może być użycie czasownika nieprzechodniego w konstrukcji z dwoma argumentami (przykłady (1a) i (1b) poniżej), czasownika przechodniego w konstrukcji z trzema argumentami (1c), fraz nietemporalnych w konstrukcji konwencjonalnie wymagającej frazy temporalnej (1d), czy przedimka nie- 
określonego $a \mathrm{w}$ połączeniu z imieniem własnym w (1e) i z rzeczownikiem niepoliczalnym (1f).

(1) (a) She jumped the horse through the fence. dosł. 'Przeskoczyła konia przez płot'

(b) She sneezed the napkin off the table. dosł. 'Skichnęła chusteczkę ze stołu'

(c) Pat sliced Chris a piece of pie. 'Pat ukroiła (dosł. 'odplastrowała') Chrisowi kawałek ciasta'

(d) three girlfriends/cigarettes later 'trzy dziewczyny/papierosy później'

(e) a Rembrandt 'Rembrandt' [obraz Rembrandta]

(f) a wine wino [gatunek wina]

We wszystkich tych przypadkach można uznać, że konstrukcja bardziej schematyczna (predykatowo-argumentowa czy frazowa) o określonych właściwościach semantycznych ,przezwycięża” pewne niezgodne z nią cechy konstrukcji mniej schematycznej (leksykalnej) i ,wymusza” reinterpretację. L. Michaelis (2004: 25) formułuje „zasadę przezwyciężania” (override principle): jeśli cechy semantyczne leksemu są niezgodne ze znaczeniem struktury, w której się pojawia, leksem dostosowuje się do znaczenia struktury. Zjawisko to jest istotnym argumentem za konstrukcyjnym sposobem opisu języka, przypisującym strukturom własności semantyczne i funkcjonalne niezależne od leksemów, w odróżnieniu od podejścia generatywnego, które zakłada, że struktura jest jedynie realizacją cech leksemów (jest „rzutowana" z leksykonu). W przykładach (1a)-(1c) czasowniki użyte są w konstrukcjach predykatowo-argumentowych mających więcej otwartych miejsc niż dany czasownik ma argumentów, przez co czynność zostaje zreinterpretowana jako reprezentująca ramę sytuacyjną charakterystyczną dla danej konstrukcji (Goldberg 2013: 19), np. na konwencjonalne znaczenie czasownika kichnać czy skakać zostaje narzucone znaczenie 'wzbudzonego ruchu obiektu'. W (1c) konstrukcja dodaje do konceptualizacji zdarzenia odbiorcę. W (1d) frazy nietemporalne otrzymują interpretację temporalną narzuconą przez konstrukcję (Fried, Östman 2004: 39). W (1e) jedna z angielskich konstrukcji 
przedimkowych, której funkcjąjest przedstawienie obiektu jako reprezentanta klasy, narzucona zostaje na nazwę własną, z definicji z nią niezgodną jako odnoszącą się do obiektu jednostkowego. Rezultatem koercji jest tu reinterpretacja nazwiska jako rzeczownika pospolitego odnoszącego się do klasy obiektów. W (1f) ta sama konstrukcja przedimkowa narzucona jest na rzeczownik niepoliczalny, co prowadzi do reinterpretacji frazy jako odnoszącej się nie do substancji, ale do jednego z jej gatunków. W perspektywie konstrukcyjnej można opisać takie przypadki jako świadome kreatywne „nad-użycie" elementów systemu językowego w celu tworzenia skondensowanych amalgamatów znaczeniowych i nowych interpretacji (Croft 2007: 504) ${ }^{7}$.

7 Koercja, a szczególnie wspomniane przypadki polisemii czasowników, są istotnym tematem badań dotyczących pogranicza leksykonu i składni (lexicon-syntax interface), podejmowanych na gruncie różnych koncepcji teoretycznych, stanowią bowiem problem opisowy dla modeli generatywnych redukujących strukturę składniową do projekcji cech leksykalnych (por. Rozwadowska 2012: 193-195). Choć zagadnienie to dalece wykracza poza temat niniejszego artykułu, w którym konstrukcyjne podejście do koercji służy wyłącznie jako przykład relacji systemu językowego do jego realizacji, warto wspomnieć, że zjawiska te są także przedmiotem opisu generatywistycznego w ramach tzw. „neokonstruktywizmu" (np. Borer 2005). Koncepcja ta jest oparta formalnie na założeniach programu minimalistycznego (autonomia składni, derywacja, gramatyka uniwersalna), ale odwraca „tradycyjną” generatywną wizję relacji leksykonu do składni, przyjmuje bowiem, że „leksykon jest zredukowany do pojęć i wiedzy encyklopedycznej i jest pozbawiony wszelkiej informacji gramatycznej, w tym kategorialnej. Z drugiej strony, dopuszczalne struktury składniowe wymuszają właściwą im interpretację, a także determinują kategorię wyrazu. Te dwa rodzaje znaczenia spotykają się i w wypadku niekompatybilności znaczenia pojęciowego ze znaczeniem strukturalnym zwycięża zawsze to drugie" (Rozwadowska 2012: 197). W takim podejściu cechy kategorialne leksemów i interpretacja argumentów czasownika wynikają wyłącznie ze struktury, derywowanej przez operację Merge (Scal). Czyniąc derywowaną strukturę składniową źródłem znaczenia, neokonstruktywizm przyjmuje więc dość specyficzną wersję myślenia konstrukcyjnego, która pozwala rozwiązać niektóre problemy opisowe dotyczące polisemii w ramach aparatu minimalistycznego, pozostawiając jednak istotne wątpliwości, np. co do roli leksykonu i ograniczeń tego rodzaju derywacji (por. polemika w Goldberg 2006: 210-213). Porównanie gramatyki konstrukcji i neokonstruktywizmu pod kątem możliwości opisu koercji i polisemii wymagałoby osobnego obszernego opracowania, na które nie ma tu miejsca, warto jednak zaznaczyć, że nawet w ramach programu minimalistycznego pojawia się myślenie konstrukcyjne. Jak dowodzi Müller (2013), niektórych danych językowych nie można opisać na gruncie minimalistycznej derywacji, co np. sugeruje konieczność sformułowania ograniczeń operacji Merge, a oba podejścia - derywacyjne i konstrukcyjne - dostarczają sobie nawzajem danych i bodźców do rozwoju, prowadzących do modyfikacji teoretycznych i lepszego zrozumienia zjawisk językowych. 
Dla porównania w (2) przytoczonych jest kilka polskich przykładów podobnych do (1), usłyszanych w reklamach telewizyjnych i transmisjach sportowych, gdzie widać bardzo wyraźnie dążenie - być może pod wpływem angielszczyzny - do kondensacji znaczeń w zwięzłych formach i/lub zaciekawienia odbiorcy niekonwencjonalnym użyciem znanych konstrukcji:

(2) (a) Nie daj się spocić. (z reklamy dezodorantu)

(b) Sześć kilo temu nie zdecydowałabym się na sesję zdjęciowa. (z reklamy środka odchudzającego)

(c) Zawodniczka pogniewała się z trenerem, ale szybko się odgniewali.

(z transmisji meczu siatkarskiego)

Uznanie takich zjawisk nie za przypadkowe usterki użycia, lecz za możliwy mechanizm twórczego wykorzystania sytemu pozwala uniknąć pewnych problemów opisowych, np. postulowania wielu wersji leksemów z różnymi zestawami własności semantycznych (np. wersji policzalnej i niepoliczalnej wielu rzeczowników angielskich). Konstrukcyjne spojrzenie na język pozwala też uchwycić fakt, że niektóre zjawiska koercyjne są dość często wykorzystywane przez użytkowników np. jęz. angielskiego w celach komunikacyjnych i że konstrukty dzięki nim powstające są zrozumiałe. Wyjaśnienie tego ostatniego faktu opiera się na założeniu, że w komunikacji zawsze dążymy do zinterpretowania wypowiedzenia, nawet jeśli nie jest ono całkowicie licencjonowane przez system, a także na kluczowej roli rozpoznawania wzorców niosących znaczenie a dostępnych użytkownikowi w systemie, nawet jeśli są niedoskonale lub tylko częściowo zrealizowane w użyciu (Fried, Östman 2004: 40; Fried 2009: 288; Steels 2013: 167).

Zjawisko koercji jest różnie traktowane w ramach różnych podejść konstrukcyjnych i wiążą się z nim rozmaite problemy teoretyczne, o których wspomnę tylko bardzo skrótowo (por. np. Ziegeler 2007). Trzeba na przykład zauważyć, że koercja, w przeciwieństwie do konwencjonalnej kreatywności językowej, czyli konstruktów licencjonowanych, nie jest w pełni przewidywalna. Można oczywiście przewidzieć, że takie zjawiska będą w języku zachodzić, ale nie można przewidzieć, że np. użycie angielskiego przedimka nieokreślonego z jakimkolwiek rzeczownikiem niepoliczalnym jest zawsze akceptowalne i da stałą interpretację (np. akceptowalne jest a mineral water 
w sensie porcji wody mineralnej, ale nie $a$ sand w sensie porcji piasku, lub a Rembrandt $\mathrm{w}$ sensie dzieła Rembrandta, ale nie a Mozart $\mathrm{w}$ sensie dzieła Mozarta). Zaobserwowane przypadki można u motywować znaczeniem użytych konstrukcji (Fried, Östman 2004: 39; Michaelis 2004: 61-62; Ziegeler 2007: 996), ale akceptowalność koercji może być różna i zależy od subtelnych, trudnych do sformalizowanego opisania czynników semantycznych (Goldberg 2006: 22) i pragmatycznych. Jednym z mechanizmów motywujących może być metonimia (Ziegeler 2007; Fried 2009: 287-288); istotną rolę odgrywa analogia. Warto wspomnieć, że pojęcie motywacji, w sensie wyjaśniania zaistniałych choć nieprzewidywalnych form przez analogię, które odgrywa istotną rolę w niektórych wersjach gramatyki konstrukcji (szczególnie u A. Goldberg 1995: 69-73, 2006: 217-219), zostało przejęte wprost od de Saussure'a (por. 1961: 138-140, 170-172). Analogia jest także elementem Sausurre'owskiego opisu zmian diachronicznych jako zaczynających się od innowacji indywidualnych prowadzących do zmian interpretacyjnych (1961: 174-178). Istotą zjawisk określanych jako koercja jest próba rozszerzenia jakiegoś mechanizmu języka na konteksty, w których konwencjonalnie się on nie stosuje; w ramach podejścia konstrukcyjnego dostrzega się, że zjawiska takie mają istotną rolę w rozwoju diachronicznym języka, prowadząc poprzez zwiększającą się częstotliwość użycia do utrwalania nowych wzorców, modyfikacji konstrukcji i pojawiania się nowych elementów w systemie $^{8}$. Warto też wspomnieć, że mechanizm analogiczny do koercji występuje w akwizycji języka jako „nadmierne uogólnienie”. Widać więc, że zjawisko to może dostarczać gramatyce konstrukcji bardzo cennych danych.

Przykład koercji został tu szerzej omówiony, ponieważ wskazuje on na bardzo dynamiczne ujęcie relacji systemu do jego realizacji w gramatyce konstrukcji. Choć system - maksymalny repertuar konstrukcji dostępnych użytkownikom danego języka - i jego użycie w postaci tworzenia konstruktów będących jednoczesnymi realizacjami wielu konstrukcji, są wyraźnie rozdzielone, co przypomina Sausurre'owskie rozdzielenie langue od parole, gramatyka konstrukcji podkreśla ciągłą ich współzależność, co wyraża się w wizji systemu opartego na uzusie i wyłaniającego się jako generalizacje częstych przypadków użycia. Ujęcie takie, szczególnie jeśli chodzi o zjawi-

8 Zastosowanie aparatu gramatyki konstrukcji do opisu procesów diachronicznych przedstawia M. Fried (2009 i 2013). 
ska diachroniczne, jest bliskie ujęciu de Saussure’a, który uznaje, że istnieje wzajemna zależność parole i langue: „mowa jednostkowa jest zarazem narzędziem i wytworem języka" (1961: 34), i że źródłem zmian diachronicznych jest parole: zmiana ,jest najpierw szerzona przez pewną liczbę jednostek, zanim wejdzie w powszechne użycie" (1961: 106). Wydaje się też, że koncepcja systemu w gramatyce konstrukcji pokrewna jest langue de Saussure'a w tym sensie, że uwzględnia jego społeczny i komunikacyjny charakter. W porównaniu $\mathrm{z}$ koncepcją generatywną, która marginalizuje kwestie znaczenia i komunikacji, abstrahując od „zbiorowości mówiącej” (Saussure 1961: 87) i koncentrując się na kompetencji gramatycznej w postaci znajomości kodu językowego przez wyidealizowanego użytkownika, podejścia kognitywne, w tym gramatyka konstrukcji, re-kontekstualizują badania nad językiem, przyznając kluczową rolę znaczeniu, konceptualizacji, funkcji i komunikacji (Geeraerts, Cuyckens 2007: 4-15). Obecność w definicji konstrukcji elementu konwencji komunikacyjnej, cel opisania wszystkich takich konwencji dostępnych użytkownikom, a także wizja akwizycji jako motywowanej potrzebą komunikacji w kontekście społeczno-kulturowym wskazuje, że wizja systemu bliska jest koncepcji de Saussure'a, który opisuje język jako fakt społeczny (Saussure 1961: 22, 28), jako „ogół nawyków językowych pozwalających danej jednostce rozumieć inne jednostki i wzajemnie być przez nie rozumianą” (Saussure 1961: 87) oraz jako „krystalizację społeczną” istniejąca , ,potencjalnie w każdym mózgu lub raczej w mózgach ogółu jednostek, gdyż w żadnej z nich nie jest kompletny; w pełni istnieje tylko w zbiorowości” (Saussure 1961: 29). Modyfikację idei de Saussure’a widać natomiast w wyraźniejszym uwzględnianiu także ogniwa pośredniego między uogólnionym zbiorowym langue a indywidualnym aktem parole, przez postrzeganie kompetencji użytkowników jako kształtującej się w indywidualnym, choć zakorzenionym społecznie procesie akwizycji, prowadzącym do wyłonienia się u nich podzbiorów owego maksymalnego zbioru konwencji określanych jako konstrukcje?

9 Rozumienie akwizycji przez de Saussure'a, choć wzmiankowane tylko in passim, jest zbieżne z wizją konstrukcyjną (i w ogólności kognitywną): „uczymy się języka ojczystego od innych ludzi, nawarstwia się on w naszym mózgu jedynie na skutek niezliczonych doświadczeń” (Saussure 1961: 34); „,[język] jest częścią społeczną mowy, znajdującą się poza jednostką, która sama nie może go ani stworzyć ani zmienić; istnieje jedynie na mocy pewnego rodzaju umowy zawartej między członkami danej społeczności. 


\section{Bibliografia}

Boss H. C., 2013, Cognitive Construction Grammar, w: T. Hoffmann, G. Trousdale (red.), The Oxford Handbook of Construction Grammar, Oxford: Oxford University Press, s. 231-252.

BogusŁawski A., 1978, Towards an operational grammar, Studia Semiotyczne 8, s. 29-90.

Borer H., 2005, The Normal Course of Events, Oxford: Oxford University Press.

Bybee J. L., 2013, Usage-based theory and exemplar representations of constructions, w: T. Hoffmann, G. Trousdale (red.), The Oxford Handbook of Construction Grammar, Oxford: Oxford University Press, s. 49-69.

CROFt W., 2007, Construction Grammar, w: D. Geeraerts, H. Cuyckens (red.), The Oxford Handbook of Cognitive Linguistics, Oxford: Oxford University Press, s. $463-508$.

DANCYGIER B., 2011, Modification and constructional blends in the use of proper names, Constructions and Frames 3(2), s. 208-235.

Diessel H., 2013, Construction Grammar and first language acquisition, w: T. Hoffmann, G. Trousdale (red.), The Oxford Handbook of Construction Grammar, Oxford: Oxford University Press, s. 347-364.

Fillmore C. J., 1988, The mechanisms of Construction Grammar, Proceedings of the Annual Meetings of Berkeley Linguistics Society 14, s. 35-55.

Fillmore C. J., Kay P., O’Connor M. C., 1988, Regularity and idiomaticity in grammatical constructions: the case of let alone, Language 64(3), s. 501-538.

Fried M., 2009, Construction Grammar as a tool for diachronic analysis, Constructions and Frames 1(2), s. 261-290.

FrIED M., 2013, Principles of constructional change, w: T. Hoffmann, G. Trousdale (red.), The Oxford Handbook of Construction Grammar, Oxford: Oxford University Press, s. 419-437.

Fried M., Östman J.-O., 2004, Construction Grammar: a thumbnail sketch, w: M. Fried, J.-O. Östman (red.), Construction Grammar in a cross-language perspective, Amsterdam: John Benjamins, s. 11-86.

Fried M., ÖstMAn J.-O., 2005. Construction Grammar and spoken language: the case of pragmatic particles, Journal of Pragmatics 37(11), s. 1752-1778.

Z drugiej strony jednostka musi odbyć pewną praktykę, by poznać jego zasady; dziecko przyswaja go sobie stopniowo" (Saussure 1961: 30). Por. model akwizycji opartej na uzusie (Tomasello 2003, 2006; Diessel 2013). 
Geeraerts D., Cuyckens H., 2007, Introducing cognitive linguistics, w: D. Geeraerts, H. Cuyckens (red.), The Oxford Handbook of Cognitive Linguistics, Oxford: Oxford University Press, s. 3-21.

Goldberg A. E., 1995, Constructions. A Construction Grammar approach to argument structure, Chicago: University of Chicago Press.

Goldberg A. E., 2003, Constructions: A new theoretical approach to language, Trends in Cognitive Sciences 7(5), s. 219-224, [online:] http://dx.doi.org/10.1016/ S1364-6613(03)00080-9.

Goldberg A. E., 2006, Constructions at work. The nature of generalizations in language, Oxford: Oxford University Press.

Goldberg A. E., 2013, Constructionist approaches, w: T. Hoffmann, G. Trousdale (red.), The Oxford Handbook of Construction Grammar, Oxford: Oxford University Press, s. 15-31.

Goldberg A. E., Casenhier D., White T. R., 2007, Constructions as categories of language, New Ideas in Psychology 25(2), s. 70-86.

Goldberg A. E, JACKendoff R., 2004, The English resultative as a family of constructions, Language 80(3), s. 532-568.

Hoffmann T., Trousdale G., 2013, Construction Grammar: introduction, w: T. Hoffmann, G. Trousdale (red.), The Oxford Handbook of Construction Grammar, Oxford: Oxford University Press, s. 1-12.

Michaelis L. A., 2004, Type shifting in Construction Grammar: an integrated approach to aspectual coercion, Cognitive Linguistics 15(1), s. 1-67.

Michaelis L. A., 2013, Sign-Based Construction Grammar, w: T. Hoffmann, G. Trousdale (red.), The Oxford Handbook of Construction Grammar, Oxford: Oxford University Press, s. 134-152.

Müller S., 2013, Unifying Everything: Some Remarks on Simpler Syntax, Construction Grammar, Minimalism and HPSG, [online:] http://hpsg.fu-berlin.de / stefan/Pub/unifying-everything.pdf, [15.11.2013].

Rozwadowska B., 2012, Neokonstruktywizm na granicy leksykonu i gramatyki, w: P. Stalmaszczyk (red.), Współczesne językoznawstwo generatywne. Podstawy metodologiczne, Łódź: Katedra Językoznawstwa Angielskiego i Ogólnego, Wydawnictwo Primum Verbum, s. 193-214.

SAussure F. DE, 1961, Kurs językoznawstwa ogólnego, tłum. K. Kasprzyk, Warszawa: Państwowe Wydawnictwo Naukowe.

Schönefeld D., 2006, Constructions, Constructions SV1-1/2006, [online:] http://elanguage.net/journals/constructions/article/view/16/36, [1.07.2013].

Steels L., 2013, Fluid Construction Grammar, w: T. Hoffmann, G. Trousdale (red.), The Oxford Handbook of Construction Grammar, Oxford: Oxford University Press, s. 153-167. 
Szymańska I., 2011, Mosaics. A Construction-Grammar-based approach to translation, Warszawa: Semper.

Szymańska I., Śpiewak G., 2006, Gramatyka konstrukcji - założenia teoretyczne i pytania metodologiczne, w: P. Stalmaszczyk (red.), Metodologie językoznawstwa. Podstawy teoretyczne, Łódź: Wydawnictwo Uniwersytetu Łódzkiego, s. $174-195$.

Tomasello M., 2003, Czy małe dzieci posiadają składniową kompetencję osób dorosłych?, tłum. W. Kubiński, w: E. Dąbrowska, W. Kubiński (red.), Akwizycja języka w świetle językoznawstwa kognitywnego, Kraków: Universitas, s. 144-222.

Tomasello M., 2006, Construction Grammar for kids, Constructions SV1-11/2006, [online:] http://elanguage.net/journals/constructions/article/view/26, [10.03.2013].

Verhagen A., 2009, The conception of constructions as complex signs. Emergence of structure and reduction to usage, Constructions and Frames 1(1), s. 119-152.

Ziegeler D., 2007, A word of caution on coercion, Journal of Pragmatics 39(5), s. $990-1028$.

\section{The Relationship Between the Language System and its Actualisations in Construction Grammar}

(summary)

Aiming to illustrate how the relationship between the language system and its actualisations in usage is envisaged in contemporary linguistic models that draw from and modify de Saussure's idea of langue and parole, the paper presents the vision of this relationship in Construction Grammar (a model developed in various variants by C.J. Fillmore, A. Goldberg, P. Kay, M. Fried and others), belonging to the widelyunderstood cognitive trend in linguistics. The focus is on the distinction between the concept of construction, a conventionalised pairing of form and meaning/function, being an element of the system, and the concept of construct, a real utterance used in communication, being an actualisation of many constructions. Construction Grammar is a usage-based model, assuming that language system generalisations emerge from frequent usage. Therefore, the article also discusses the phenomenon of coercion, i.e. "stretching" constructions to combine with "unfitting" lexemes, seen not as a breach of the system but as one of the mechanisms of its creative use to construct new meanings, which may lead to changes in constructions, to the emergence of new ones, and hence to the modification of the system. 
